\title{
INVESTIGATING COMPLEXITY OF INTERSECTORAL COLLABORATION: CONTEXTUAL FRAMEWORK FOR RESEARCH
}

\begin{abstract}
Purpose - The aim of this paper is to explore the concept of intersectoral collaboration and to compile context-sensitive framework for further research in the field.

Design/methodology/approach - Inductive review of scientific literature as well as theoretical modelling methods were applied.

Findings -Research limitations/implications - Recent literature revealed that the content of the intersectoral collaboration concept did not change significantly. The scientific discourse has been complemented by more methodological and practical observations that allow to improve collaboration management and processes and enhance possibility to achieve planned joint goal of multilateral initiative. Nevertheless, there is still insufficient literature that explains what issues are a) common for explicit collaboration and b) critical for performance in practice. In mostly, intersectoral collaboration analysis is based on successful cases. It would be useful to consider not only key success factors but also why intersectoral collaboration fails.

Practical implications - In scientific discourse intersectoral collaboration is recognized as an instrument for overcoming complexity of issues in public and private sectors and NGOs due to its successful application in many cases. However, it cannot give its full advantages due to the weak understanding regarding the main affecting factors, most recent obstacles as well as different contexts throughout its application process. Perceived effectiveness of intersectoral collaboration might be reached with a help of aggregated and professionally applied scientific investigations in the field taking into account specific features of particular discourses. Thus, the contextual model compiled and insights on intersectoral collaboration made in the article can be used as a further research framework in the field.

Originality/Value - The complexity of intersectoral collaboration was discussed and contextsensitive framework for research was presented.

Keywords: intersectoral collaboration; multilateral interaction; management; leadership; success factors, research prospects.

Research type: literature review, conceptual paper.

JEL classification:

D85- Network Formation and Analysis: Theory

L14 - Transactional Relationships; Contracts and Reputation; Networks

P13 - Cooperative Enterprises
\end{abstract}

\footnotetext{
${ }^{1}$ PhD., professor, Mykolas Romeris University, Lithuania, agotar@mruni.eu

${ }^{2}$ Mgr., Lithuanian Institute of Agrarian Economics, Lithuania, lina.baranauskaite@laei.lt
} 


\section{Introduction}

The increasing demand for social well-being of people round the world goes in parallel with processes of tight competition in globalized value chains. There is still viable strong productivity approach on the development processes for economic growth and profits as core benefits ahead. At the same time heritage from productivism era already demonstrate greatly disappointing results of such approach. Devaluation of core human as well as organizational values in overall competitive environment, encompassed by various scandals due to unfair market plays, accelerated the origination of new organizational models that are applicable in continuously changing globalized environment to ensure reputation, trust and success in a long run. In all sectors and spheres of human activity the demand for fair competition in the changing micro and macro environments remain driven by such factors as technological progress, globalization of markets, diminishing role of economic constraints, accelerated rates of collaboration, emergence of creative society evolved from knowledge and information era, accordingly - increased consumer awareness and new habits.

Interaction between cultural, social, economic and political factors leads to the emergence of complex problems. Vast amount of evidence calls for new solution that cannot be found by a single actor from one sector. As Beinecke (2009) states, public sector issues become more complicated. Due to the limited resources, solutions of such problems might be found via collaboration among sectors, since inter-sectoral relations might provide demanded capabilities to catalyze possible solutions.

In scientific discourse, intersectoral collaboration gained the importance at the end of the $20^{\text {th }}$ century. In Rio de Janeiro World Summit on Sustainable Development (WSSD) 1992 issued sustainable development goals by stressing the urgent need of acting together among all sectors and spheres of human activity in reaching them. It was stated that many issues in the world remain unsolved since it was done in separate actions. And the way of acting via intersectoral collaboration might help in finding solutions for main obstacles to overcome in reaching social equity, environmental health and economic wealth. Governance of all components includes resources from different sectors, which are necessary to reach sustainability goals, approved in 2002 WSSD in Johannesburg (Hens \& Nath 2003; Norris 2005; Eweje 2007) via intersectoral collaboration. Since then, many authors (e.g. Van Huijstee et al. 2007, Borges et al. 2016 et al.) offer intersectoral collaboration as most optimal tool moreover key element for managing the public sector and solving public sector issues.

Intersectoral collaboration is being researched from a different point of view. The authors present their insights in specific terms used in their sphere and interpret concept in different areas. Despite the fact of intersectoral collaboration is recognized as an instrument for overcoming complexity of issues in public and private sectors and NGOs due to its successful application in many cases, interdisciplinarity of the phenomenon leads to the variety in terminology and thus hinders an ability to communicate to representatives of different fields and, most importantly, to increase the efficiency of intersectoral collaboration in practice. On the other hand, intersectoral collaboration cannot give its full advantages due to the weak understanding regarding the main affecting factors, most recent obstacles as well as different contexts throughout its application process. Perceived effectiveness of intersectoral collaboration might be reached with a help of aggregate investigations considering specific features of particular contexts.

Based on this relevance, the goal of the article is to investigate a complexity of intersectoral collaboration and to compile a context-sensitive framework for further research in the field. With this aim, general outlines of the concept were delineated, the contextual 
model of intersectoral collaboration was composed and novelty of the discourse on intersectoral collaboration in the latest scientific publications was discussed.

For the research, inductive review and systemizing of scientific literature as well as theoretical modelling methods were applied.

The article consists of an introduction and three main parts that are i) theoretical background of intersectoral collaboration, which allowed to highlight the essential determinants for which the consensus of scientists has been achieved; ii) methodology; iii) an analysis of the latest publications on intersectoral collaboration topics, which allowed the identification of intersectoral collaboration areas that have received the greatest attention from scientists, as well as the elements that are discussed less frequently. At the end of the article, conclusions are provided.

\section{Theoretical background}

\section{Outlines of the concept of intersectoral collaboration}

Researchers, depending on the area represented and the scale of the problem under investigation, distinguish the different intersectoral collaboration capabilities, interference and success factors. Huijstee at al. (2007) summarize the two main perspectives of the scientific approach - institutional and participatory. Looking from institutional context, intersectoral collaboration provides new management capabilities (looks at partnerships as new arrangements, emerging naturally as it were out of their institutional context). From the institutional standpoint, most authors are investigating what intersectoral collaboration role could be and what functions should be performed in a presumed new global environmental governance regime. From this point of view of intersectoral collaboration, researchers are investigating the driving forces behind the collaboration trend and the institutional implication of this trend (Huijstee et al., 2007). Cases show that collaborators can see intersectoral collaboration as an instrument for achieving their own individual goals or solving problems. Therefore, it is important to find solutions that would allow sustainability to be extended to a wider extent: in dimensions of social life, environment and economic effectiveness (Borges at al., 2016; Whiteside, 2004).

It can be stated that intersectoral collaboration has a variety of forms that depend on the specific objectives, the number and nature of the involved subjects, the activities carried out and their intensity, etc. (Huijsteeet et al 2007, Francken, Leroy, 2007). In addition, different authors point to different key areas of action and relation management (Curtis et al., 2011; Grossmann, 2012; Olson et al.,2011). Nevertheless, in general, the authors discuss about only three influencing areas for intersectoral collaboration: external and internal environment, policy made by decision-making authorities, and management of collaboration processes and relations. As this article focuses on the very concept of intersectoral collaboration, it is further analyzed at the institutional level.

\section{Complexity of intersectoral collaboration}

Looking at intersectoral collaboration from the point of view of organization of multilateral performance, five broad areas of focus can be distinguished:

1. Collaboration prerequisites;

2. Scope of collaboration;

3. Type of the interaction;

4. Efficiency of the collaboration process; 
5. Management of the activities and interactions between collaboration bodies.

In the scientific discourse, the mandatory prerequisites of intersectoral collaboration are the following:

- The common goal which defines the expected benefits;

- Mutual trust between parties of collaboration;

- Sharing of the tasks by committing to share the risk, time and other resources.

A common goal is the key to initiate intersectoral collaboration. According to Huijsteeet et al. (2007), some researchers explain why common goal is important (e.g. Glasbergen and Groenenberg (2001) while others refer to it as an unquestionable precondition for sustainable development (e.g. Arts, 2006). However, authors agree on one: the goal must be precisely defined, achievable and measurable in a language which is understandable to all actors. The purpose must be properly communicated, preferably in writing (Olson et al. 2011). Mattessich et al. (1992) argue that unique common goal should clearly differ from personal aims of members, and a vision of partners must match. Intersectoral collaboration developers should be focused on long-term perspective, as short-term goals and outcomes does not form interpersonal relationships and does not increase confidence (Grossmann, 2012).

Trust and commitment as the fundament is e.g. attributed to many authors (Borges et al. 2016; Olson et al. 2011, Ansari, Phillips 2001, Whiteside 2004). Trust has many features and benefits, it reduces the feeling of insecurity and risk. Instead of formal rules, trust makes collaboration less rigorous and more creative. Trust is both a result and a basis of collaboration. Trust does a major impact on changing people, situations, priorities and culture. The key to creating a climate of trust is to choose the right partners for a mutually beneficial relationship (Grossmann, 2012).

When discussing the impact of the scope of collaboration, to achieve planned results, the importance of the environment as an intersectoral collaboration medium should be highlighted. Environmental elements might be divided into levels. The micro level should be understood as the arena of actions of collaborating actors (groups, teams as well as individuals). In the meso level, the nature of intersectoral collaboration is shaped by the organizational culture and authorities of each interacting entity. Finally, macro level encompasses the legal and economic environment regulating the performance of institutions in different sectors.

In reviewed literature the authors discuss about the type of intersectoral interaction since the overall goal set by the organizations requires an interpolation of resources and efforts. According to the integrity of the links of organizations, seven forms of interactions are distinguished in the implementation of organizational and inter-organizational goals: integrated collaboration, partnership, union, cooperation, networks, coopetition and competition (Raišienè et al. 2015). As the benefits of collaboration are gained in more integrated forms of interaction, the development of collaboration should be at least as much as taken care of as the objectives of the joint activity.

The efficiency of collaboration process is often identified by researchers as having the greatest impact on the success of collaboration. Huijsteeet et al (2007), Curtis et al. (2011), Grossmann (2012), Mattessich et al. (1992), Olson et al. (2011) etc. have researched collaboration process. It can be noted that the factors that determine success of collaboration process coincide only partially. For example, after studying collaborative case studies, Olson et al. (2011) summarized successful collaboration factors, and this is:

- Purposeful, clear, common and change-motivating goal;

- Matching missions, strategies and values;

- Commitment to cooperate;

- The perception of the benefits of collaboration; 
- Clear, defined roles of the participants;

- Creation of a management structure and division of powers;

- Inclusion of all members in decision-making and processes;

- Sufficient resources (funds, time);

- Open and frequent communication as well as informal communication;

- Productive relationships (respect and trust between partners and constructive criticism, good interpersonal relations between partners and among managers, promotion of development, etc.). Meanwhile Curtis et al. (2011) summed up Mattessich et al (2001), Austin (2000), Ovretveit et al.(2002) and Casey (2008) works and distinguished such of key factors as: trust, respect, inclusiveness, benefit, time, commitment, timely decision making, flexibility, role clarity, decision-making process, adaptability, work load/amount, pace of work, communication, leader communication, knowledge of goals, reasonable of goals, dedication to success, comparison to other collaborations, resources/people power, skills of leaders. As can be seen, some of these factors coincide with the intersectoral collaboration prerequisites. Finally, for example, Grossmann (2012) studied successful examples of collaboration between different companies and proposed criteria for intersectoral success:

- Collaboration as an autonomous system organization;

- Focusing on partners' abilities and competences;

- An assessment of the possible impact of people and their interrelationships;

- Determination of common aspects of activity;

- Perception of mutual benefit;

- Establishment of a control system;

- Correct management of the collaboration process;

- Creation of internal requirements (rules);

- Assurance of effective teamwork;

- Coordination of different interests and opinions;

- Mutual trust.

The latter - mutual trust - is considered as an indisputable basis for collaboration. Furthermore, Grossmann (2012) claims that collaboration does not come naturally or from external necessity. On the contrary, participating organizations and individuals need to overcome a complex process to create a link that connects these important organizations. Collaborating people face a significant challenge as to how to reconcile different working traditions, practices, cultural peculiarities and certain limitations of the partners. The commitment of the participants and the contribution of each of them is necessary for the success of the collaboration. A well-thought-out structure is important, but it's not enough the decisive factor is the negotiation process, the quality of communication and depth for reaching common consensus and decision making. Without the sincere commitment of the participants, the planned result will not be achieved.

Management of the activities and interactions between collaboration bodies is best explained by the characteristics of process and resource matching. It includes support and infrastructure to enable people to work and achieve a common goal. When planning resources and processes it is important to define and detail the agenda and actions, their implementation and development, to design control mechanisms. To implement programs of high-level public administration bodies or projects that involve more than two sectors in multilateral projects it is advised to first create and test the pilot model of management of the process (Axelsson, 2009). Often for the justification of intersectoral collaboration and empowerment of participants, regulation changes are required before planning and allocation of processes and resources. It is: policy formation, alignment of strategies, procedures, longterm and short-term tasks, and their management and improvement. 
In terms of interaction management, two main challenges are identified, that are communication and motivation.

Gazley (2014) studied motivation for collaboration and distinguished personal traits, direct and indirect experience, environmental impact, participants' education and learning. Motivation is also influenced by trust, which depends to a large extent on leaders' support (Dinh et al. 2014). Motivation increases when colleagues believe that the benefits will be higher than the contribution. Respect among collaborators will be strengthened if members perceive and accept values such as engagement and equality of members. Collaborating members must treat each other as equivalent partners, since this will only create horizontal relationships which is exactly what requires the principle of genuine collaboration. Secondly, organizational empathy is important for each member to understand what pressure is felt and what constraints another member is facing. Each member has obligations to the parent organization, but at the same time should try to understand the position and attitude of other members. (Perrault at al., 2011).

Emphasizing the perspective and quality of the relationship, Perrault et al., (2011) states that intersectoral collaboration is a long-term relationship in which individual organizations create new structures with common goals, together defined mission, discussed structure and mutually donated resources.

Based on discussed components, a model that reveals the complexity of the phenomenon of intersectoral collaboration was compiled. It also demonstrates the interconnections between the components (Figure 1).

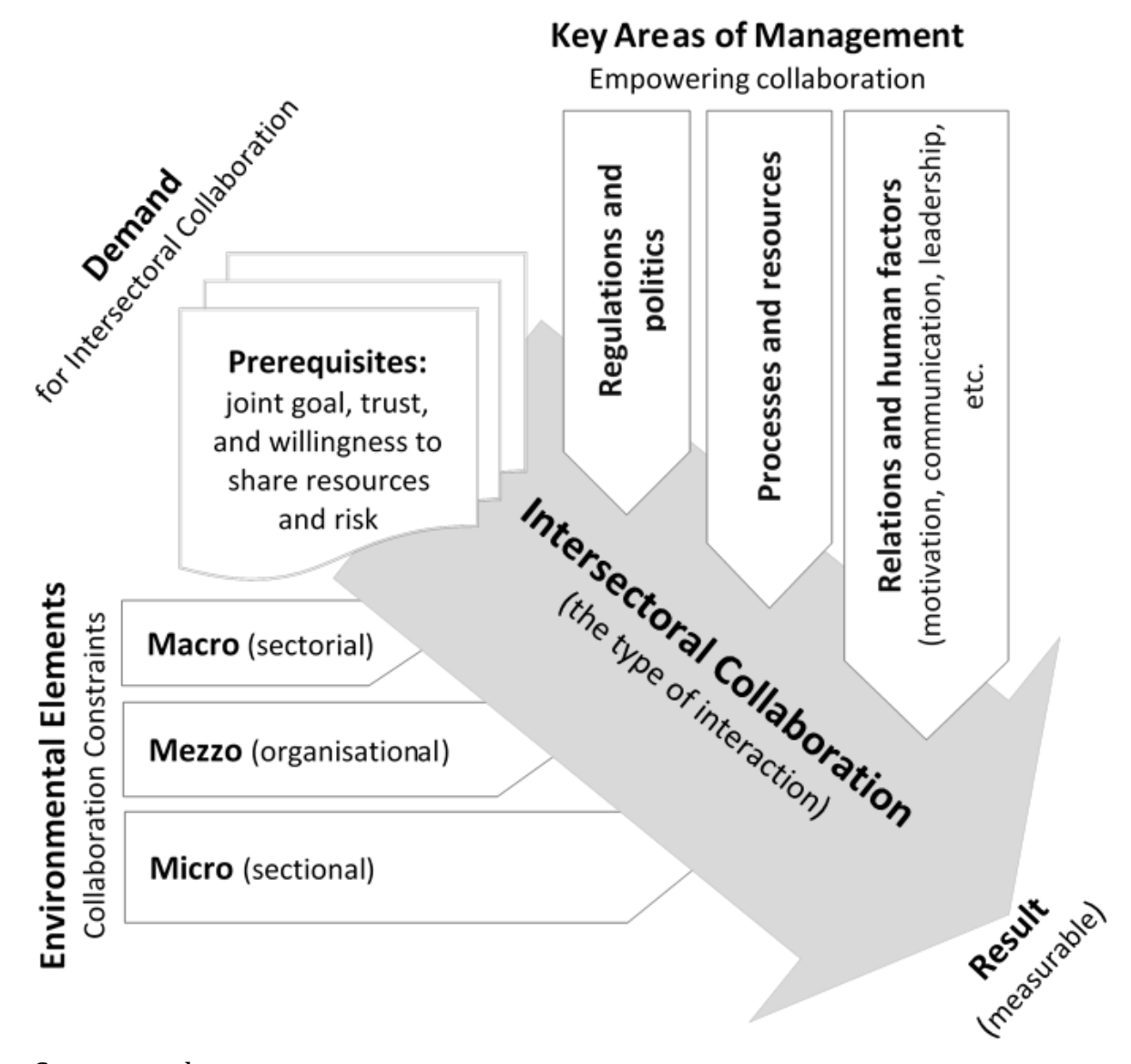

Source: authors

Figure 1. Model for the complexity of intersectoral collaboration 


\section{Research methodology}

To find out how the concept of intersectoral collaboration changed in scientific discourse in comparison of different periods, Valaitis at al. (2012) methodological approach was selected and a scoping review was done.

For the review, period of the last five years was selected $(2013-2017)$. The scientific publication search engine Scholar Google was used for the search of articles (https://scholar.google.lt/). Articles were searched by keyword „intersectoral collaboration”. In the beginning, keyword „inter-organizational collaboration” was also used in the search field, since it was observed that in some cases the examined interaction takes place between different organizations but in the same sector. 58 articles were found under these keywords. 5 of these had to be rejected because their content has poorly correlated with keywords. Out of these articles, 18 articles were selected based on these criteria:

1. Scientific paper (project report, methodological, etc. non-scientific publications have been rejected);

2. Full text (extended abstracts were rejected);

3. The focus was on the concept of intersectoral collaboration (the articles describing cases of a one-off or a project nature were rejected).

Each of the remain 18 papers were analyzed with a focus on the goals set in this article and the sections mentioned above: collaboration prerequisites; scope of collaboration; type of the interaction; efficiency of the collaboration process; management of the activities and interactions between collaboration bodies.

The review of recent publications has made it possible to compare past and newer knowledge of intersectoral collaboration and to develop a contextual model of intersectoral collaboration complexity.

\section{Results}

In the analyzed period, intersectoral collaboration was mainly studied in sectors such as health and education. The conceptual issues of intersectoral collaboration were examined by Kožuch et al. (2013; 2016a; 2016b), Versteele (2016), Teslenko, Digilina (2015), Hendriks et al. (2015), Dhimal, Karki (2014). The justification for the need of intersectoral collaboration was examined by Dhimal et al. (2014); Lander (2014); Teslenko (2014). Intersectoral collaboration key implementation areas and key success factors studied Kožuch (2013), Freeman et al. (2013), Hendriks et al. (2015), Spear (2013), Brucherta et al. (2017). The effectiveness of intersectoral collaboration studied Oelke et al. (2016), Pucher et al. (2015), Freeman et al. (2013), Chircop et al. (2015), organizational structure and processes was examined by Dhimal, Karki (2014), Miller (2016), Chirop et al. (2015), Pucher et al. (2015), Bingqin et al. (2015), Tooher et al. (2017) etc.

The underlying insight of the scoping review is that, compared with the earlier period, the content of the concept of intersectoral collaboration has not changed significantly. The scientific discourse has been complemented by more methodological and practical notes and observations that allow improving collaboration management and processes (Figure 2). 


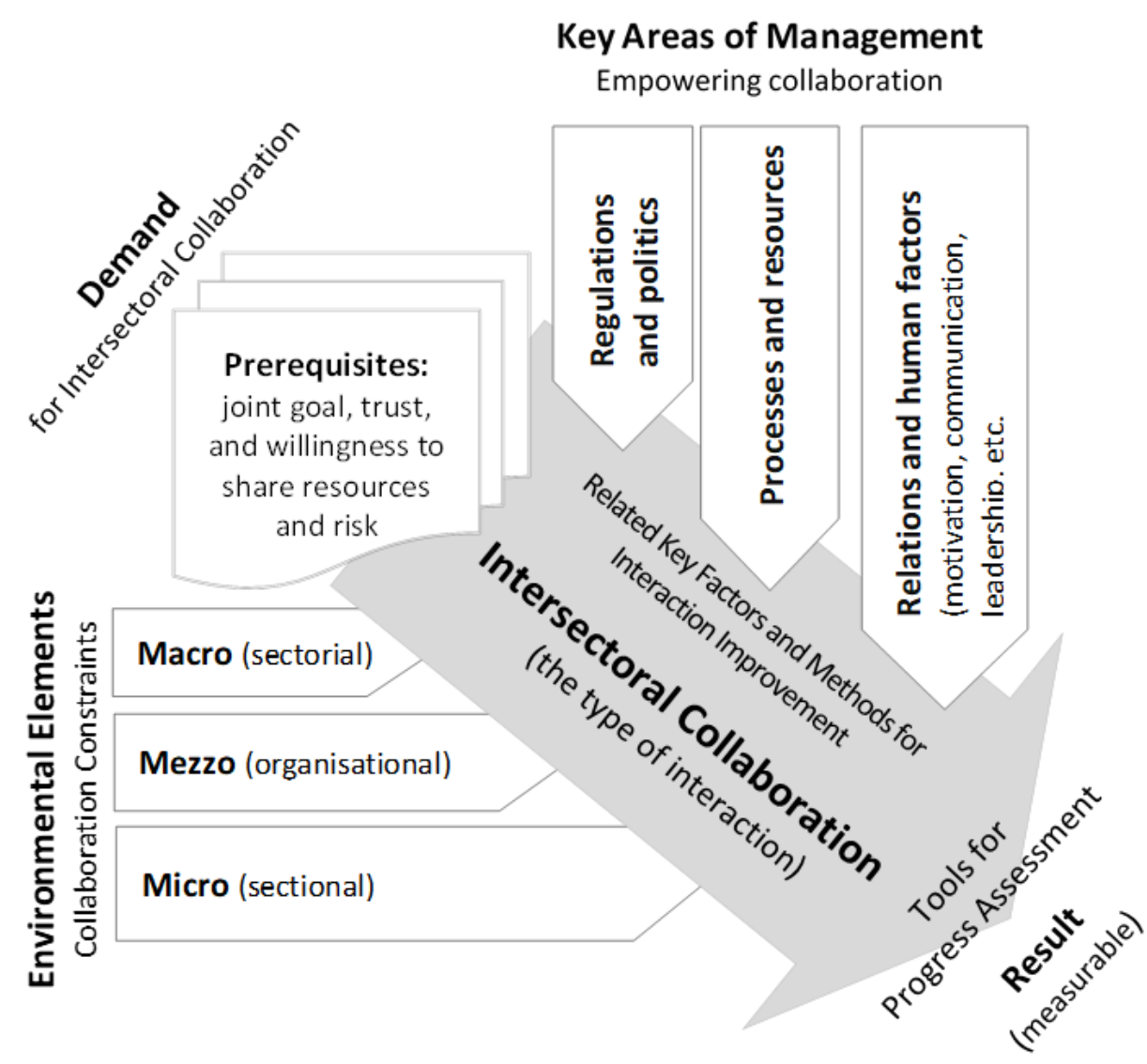

Source: authors

\section{Figure 2. The model of intersectoral collaboration complexity based on a literature of the period 2013-2017}

Literature analysis has also enabled to mention some of the restraints due to the gaps in the development of intersectoral collaboration. It can be observed that it is still insufficiently clear how the relationship reveals itself between practice in the conceptual framework of constructs (Pucher, 2015). The relatively small number of examples analyzed in the literature does not allow to at least be more confident about what and how in the practice of collaboration works (Hendriks et al., 2015).

Finally, the literature review highlighted the prospects of further research. Freeman et al. (2013) notes that still little is known about management of stakeholders when implementing the intersectoral projects; according to Miller (2016) relatively little is known about international aspects of intersectoral collaboration; Chircop (2015) suggests to continue clarifying intersectoral collaboration concept; Hendriks et al. (2015) stresses the need to examine in broader range collaborative behavior; Bingqin et al. (2015) observes that it is not clear how the result of collaboration is influenced by an approach (top-down or bottom-up approach) when developing intersectoral improvement plans. It is also noteworthy that, nevertheless, most authors do not speak about prospects for future research, but more are focused on alternatives to the problem being solved. Thus, the need does not diminish for intersectoral collaboration investigators to observe the practice and identify relevant multilateral problems. 


\section{Conclusions}

When indicating outlines of intersectoral collaboration, researchers discuss three main influencing areas of intersectoral interaction: external and internal environment, policy made by decision-making authorities, and management of collaboration processes and relations. The latter area is mostly discussed in scientific literature, and it is considered to require special attention to the issues caused by the human factor and constant changes in actual situation.

From the point of implementation of interoperability, intersectoral collaboration is distinguished by five domains that are important to achieve the effectiveness and efficiency: i) obligatory prerequisites to start interaction, ii) a type of interaction which depends on a mutual goal, iii) the collaboration process, iv) the scope of collaboration characterized by the number of parties, and $v$ ) the management of the activities and relations between collaborating actors. The complexity of these factors determines the complexity of intersectoral collaboration and the ongoing challenges.

Based on the analysis of scientific publications, the concept of intersectoral collaboration was investigated and context-sensitive framework for research in the field was presented.

Recent literature revealed that the content of the intersectoral collaboration concept did not change significantly. The scientific discourse has been complemented by more methodological and practical notes and observations that allow improving collaboration management and processes, and to enlarge possibility to achieve planned joint goal of multilateral initiative. Also, it turned out that there is still insufficient literature that explains what factors are common for explicit collaboration and critical for performance in practice. In mostly, intersectoral collaboration analysis is based on successful cases. Nevertheless, it would be useful to consider not only key success factors but also why intersectoral collaboration fails.

The composed model and made observations can be used as a further research framework.

\section{References}

1. Ansari W.E., Phillips C. (2001) Partnerships, community participation and intersectoral collaboration in South Africa. Journal of Interprofessional Care, Vol. 15, No. 2: 119-132.

2. Arts B., Leroy P., (2006) Institutional Dynamics in Environmental Governance. In: Arts B., Leroy P. (eds.) Institutional Dynamics in Environmental Governance. Springer, Dordrecht, p.1-19.

3. Austin J. (2000) The collaboration challenge: How non-profits and businesses succeed through strategic alliances. San Francisco, CA: Jossey-Bass.

4. Axelsson S. B., Axelsson R. (2009) From territoriality to altruism in interprofessional collaboration and leadership. Journal of Interprofessional Care. Vol. 23, No. 4: 320-330.

5. Beinecke R. H. (2009) Introduction: Leadership for Wicked Problems. Innovation Journal. Vol. 14 No. 1:1-17.

6. Borges M.A., Soares A.L., Dandolini G.A. (2016) Collaborative Networks as Ways to Improve Crosssector Collaboration in Social Innovation: An Exploratory Study.

7. Brüchert T., Quentin P., Baumgart S. (2017) Intersectoral collaboration of public health and urban planning for promotion of mobility and healthy ageing: protocol of the AFOOT project ORCID. Icon \& Gabriele Bolte, Vol.1, No.1., p. 83-88.

8. Casey, M. (2008). Partnership - success factors of interorganizational relationships. Journal of Nur Collaboration, No.16: 72-83.

9. Chircop A. (2015) Evidence on how to practice intersectoral collaboration for health equity: a scoping review. Critical Public Health, Vol. 25, No. 2: 178-191.

10. Dhimal M., Karki K.B. (2014) The hidden burden of Neglected Tropical Diseases: a call for intersectoral collaboration in Nepal. Journal of Nepal Health Res. Counc., Vol. 12, No. 3: I-II. 
11. Dinh, J., Lord, R., Garnder, W., Meuser, J., Liden, R.C., Hu, J. (2014) Leadership theory and research in the new millennium: current theoretical trends and changing perspectives. Leadership, No. 25 (1): 36-62.

12. Eweje G. (2007) Strategic partnerships between MNEs and civil society: the post-WSSD perspectives. Sustain Development, Vol. 15, No. 1: 15 - 27.

13. Freeman M.C., Ogden S, Jacobson J, Abbott D, Addiss D.G., et al. (2013) Integration of Water, Sanitation, and Hygiene for the Prevention and Control of Neglected Tropical Diseases: A Rationale for InterSectoral Collaboration. PLoS Neglected Tropical Diseases, No. 7(9): e2439.

14. Gazley B. (2008) Intersectoral Collaboration and the Motivation to Collaborate: Toward an Integrated Theory. Big Ideas in Collaborative Public Management, Routledge, p. 288.

15. Glasbergen P. (2007) Setting the scene: the partnership paradigm in the making. In: Glasbergen P., Biermann F., Mol A. P. J. (eds). Partnerships, Governance and Sustainable Development- Reflections on Theory and practice. Cheltenham, UK: Edward Elgar, p.6-25.

16. Grossmann R., Lobnig H., Scala K, Stadlober M. (2012) Facilitating Collaboration in Public Management, Information Age Publishing, p.219.

17. Hendriks A.M., Jansen M.V.J., Gubbels J.S., De Vries N.K., Mollemane G., Kremers S.P.J. (2015) Local government officials' views on intersectoral collaboration within their organization - A qualitative exploration. Health Policy and Technology, Vol. 4:47-57.

18. Henneman E. A., Lee J. L., Cohen J. I. (1995). Collaboration: A Concept Analysis. Journal of Advanced Nursing, No. 21: 103-109.

19. Hens L, Nath B. (2003) The Johannesburg Conference. Environ Dev Sustain, 5:7-39.

20. Huijstee M.M., Francken M., Leroy P. (2007) Partnerships for sustainable development: a review of current literature. Environmental Sciences, No.4:2, 75-89.

21. Kozuch B., et al. (2016b) Factors of effective inter-organizational collaboration: a framework for public management. Ap. Transylvanian Review of Administrative Sciences, No. 47: 97-115.

22. Kożuch B., Sienkiewicz-Małyjurek K. (2013) Inter-organisational Collaboration and Public Sector Innovativeness - the Case of Poland. Contemporary Management, Vol. 12, No. 3: 8-25.

23. Kożuch B., Sienkiewicz-Małyjurek K. (2016a) Key Factors of Inter-organisational Collaboration in the Public Sector and Their Strength. International Journal of Contemporary Management, Vol. 15, No. 3: $123-144$.

24. Lander B. (2014) The Role of Institutions and Capital in Intersectoral Collaboration: Infection and Immunity Research and Development Collaboration in Vancouver. Review of Policy Research, Vol. 31, No. 5: 390 407.

25. Mattessich P.W., Monsey B.R. (1992) Collaboration: What Makes It Work. A Review of Research Literature on Factors Influencing Successful Collaboration. Amherst H. Wilder Foundation, 919 Lafond, St. Paul, MN 55104.

26. Mattessich P.W., Monsey B.R., Murray-Close M. (2001) Collaboration: What Makes It Work. $2^{\text {nd. }}$. St Paul, MN: Fieldstone Alliance.

27. Miller J. M. (2016) International inter-sectoral collaboration in university research centres: innovation systems in the United States and beyond in comparative perspective. Asia Pacific Journal of Public Administration, Vol. 38, No.4: 239-250.

28. Norris C. (2005) Partnerships for sustainable development. The role of type II agreements. In: Kallhauge A.C., Sjostedt G., Corell E. (eds). Global challenges: Furthering the multilateral process for sustainable development. Sheffield, UK: Greenleaf Publishing, p. 210-230.

29. Oelke N.D., Stiphout M.L., Suter E., Hepp S., Rostami M., Birney A., Janke R., Van Vliet-Brown Ch. (2016) Measuring intersectoral collaboration in a health care setting: A knowledge synthesis. International Journal of Integrated Care. No.16(6): A11.

30. Olson C.A, Balmer J.T., Mejicano R.G.C. (2011) Factors contributing to successful interorganizational collaboration: The case of CS2day. Journal of Continuing Education in the Health professions, No.31 (S1): S12.

31. Øvretveit J., Bate P., Cleary P. et al. (2002) Quality collaboratives: lessons from research. Qual Saf Health Care. No. 11(4): 345-351.

32. Perrault, Ellen et al. (2011) Working Together in Collaborations: Successful Process Factors for Community Collaboration. Administration in Social Work, Vol. 35, No. 3: 282-98.

33. Pucher K.K., Candel M.J.J.M., Boot N.M.W.M., van Raak A.J.A., de Vries N. K., (2015b) A multiple-case study of intersectoral collaboration in comprehensive school health promotion using the Diagnosis of Sustainable Collaboration (DISC) model. Health Education, Vol. 115, No. 3/4: 301-321.

34. Pucher K.K., Candel M.J.J.M., Krumeich A., Boot N.M.W.M., De Vries N.K. (2015a) Effectiveness of a systematic approach to promote intersectoral collaboration in comprehensive school health promotion-a multiple-case study using quantitative and qualitative data. BMC Public Health, No. 15:613.

35. Raišienè A. G., Korsakienė R., Lace N. (2015) How Do Inter-Institutional Teams Succeed? A Case of National Project. Economics \& Sociology: Journal of Scientific Papers, Vol. 8, No. 1: 7-18. 
36. Spear R.C. (2013) Commentary by Spear, R. on "Integration of Water, Sanitation, and Hygiene for the Prevention and Control of Neglected Tropical Diseases: A Rationale for Inter-Sectoral Collaboration:" Can the Control of NTDs Profit from a Good WASH? PLoS Neglected Tropical Diseases, No.7(9): e2473.

37. Teslenko B., Digilina O.B. (2014) The Potential of Intersectoral Collaboration for Development of Russian regions. Life Sci J, Vol. 11(8):218-220.

38. Tooher R., Collins J., Braunack-Mayer A., Burgess T., Skinner S.R., O'Keefe M., Watson M., Marshall H.S. (2017) Intersectoral collaboration to implement school-based health programmes: Australian perspectives. Journal Cities \& Health Vol. 32, No. 2: 312-321.

39. Valaitis R., Martin-Misener R., Wong S.T., MacDonald M. (2012) Methods, strategies and technologies used to conduct a scoping literature review of collaboration between primary care and public health. Primary Health Care Research \& Development. Vol. 13, No.3: 219-236.

40. Versteele L. (2016) Governance of interorganizational and intersectoral collaboration: the Care Living Lab experience. European Journal of Public Health, Vol. 26, No.1, suppl.1.

41. Whiteside M. (2004) The challenge of interdisciplinary collaboration in addressing the social determinants. Australian Social Work. Vol. 57 No.4:381-393.

42. WSSD. Annual Report (1992) World Summit on sustainable Development in Rio de Janeiro [online] [accessed 4 June 2018]. Available from Internet: <http://www.un.org/documents/ga/conf151/aconf151261annex1.htm>

43. WSSD. Annual Report (2002) World Summit on sustainable Development in in Johannesburg [online] [accessed 4 June 2018]. Available from Internet: <http://www.un-documents.net/aconf199-20.pdf>. 